\title{
Johns Hopkins: A Canadian medical school?
}

Cite as: CMAJ 2017 July 4;189:E893-4. doi: 10.1503/cmaj.170284

uestions about the special role Canadians play globally have new resonance as we observe the strikingly different leadership styles of Justin Trudeau and Donald Trump. William Osler, first chief of medicine at Johns Hopkins Hospital in Baltimore, was Canadian. Turns out, there were plenty of Canadians in early leadership roles at Hopkins. Shortly before his death in 1919, Osler remarked upon how "well and gently" his equally influential American cofounders had accepted the "Canadian personality" during the institution's early development. ${ }^{1}$ There were also whispered criticisms, however, that too many Canadians were calling the shots at the new and important medical university. ${ }^{1}$

The innovative and idiosyncratic teaching methods in medicine and nursing that constituted the Hopkins model were emulated by medical and nursing schools across North America. To what extent did a distinctly Canadian influence exert itself in terms of institutional dynamics, teaching or research? I am currently exploring this question using archival collections and published works. Here, I highlight three important dimensions for investigation: the perception, selection and selfidentification of Canadians in key leadership roles at Johns Hopkins during its first 50 years (1889-1939).

Various factors explain why the Johns Hopkins medical model evolved as it did. Central was the principle that hospitals were instruments of nursing and medical education, and that the latter required bedside instruction and laboratory experience.
This vision incorporated multiple European and British traditions in new ways, and the university's trustees had ample resources to execute it (despite later shortfalls), which attracted talented faculty. ${ }^{2}$ John Shaw Billings, hired to design the visionary teaching hospital, acknowledged that its success would not depend on his architectural choices, but on the careful selection of "proper and suitable persons" - Billings specified six men and one or two women "to be the soul and motive power of the institution." ${ }^{3}$ The early leaders at Johns Hopkins were charged with institutionalizing state-of-the-art therapeutics, curricula and research, and they handpicked individuals for admission and promotion. ${ }^{4}$

The influence of individual personalities and collective identities are also important

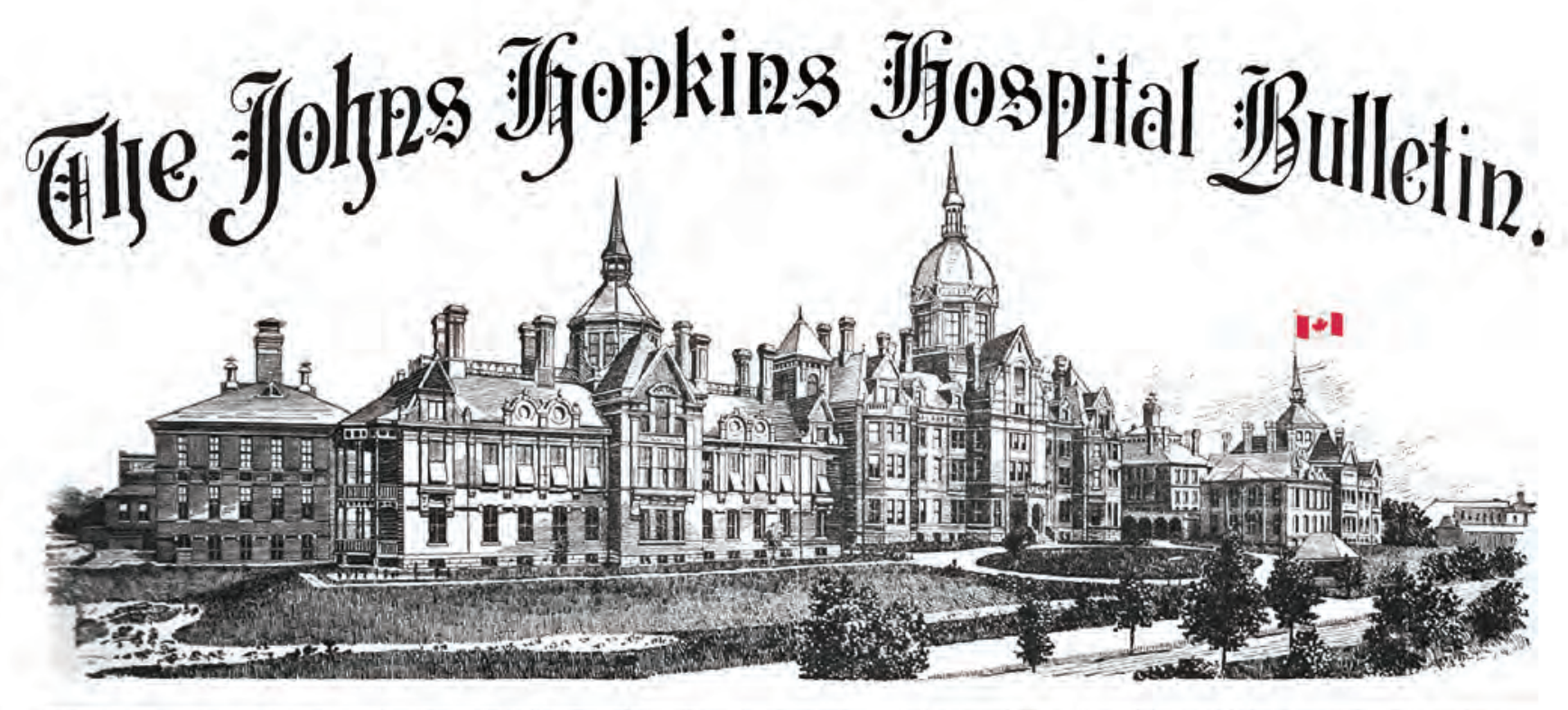

Volume I. - No. 1.]

BALTIMORE, DECEMBER, 1889.

[Price, 15 Cents.

Figure 1: Masthead of the first issue of The Johns Hopkins Hospital Bulletin (with Canadian flag playfully superimposed). This issue inspired Toronto physician Lewellys Barker to apply to do postgraduate work at Hopkins; he eventually became chief of medicine. (Source: Welch Library, Johns Hopkins Medical Institutions) 
explanatory frameworks. Biographers such as Michael Bliss examine how the circumstances and choices of key figures shaped Hopkins. ${ }^{5}$ One writer argues that shared membership among early Hopkins leaders in Yale University's Skull and Bones society influenced developments in Baltimore. ${ }^{6}$ Likewise, I employ the concept of a distinctly "Canadian" identity as an analytic lens and potential causal factor.

Among the inaugural faculty - William Osler (Chief of Medicine), William Welch (Chief of Pathology), William Halsted (Chief of Surgery) and Howard Kelly (Chief of Gynecology) - Osler was the sole Canadian. Three of their four successors were Canadians, as were the first four female superintendents of the nursing school (Isabelle Hampton, Adelaide Nutting, Georgina Ross and Elsie Lawler). Data collected thus far generate a preliminary sketch of Canadian representation within the early, influential leadership. It includes the department chiefs mentioned above, their senior residents and the nursing superintendents. Between 1889 and 1939, $37.8 \%$ of this core leadership was Canadian. As a contextual barometer, according to United States Census Bureau data for these decades, Canadians represented roughly $1 \%$ of the country's population, and $14 \%$ of incoming Canadian migrants were educated professionals.

Was this a disproportionate number of Canadian leaders at the new institution poised to set the course for North American medicine? That perception certainly existed. Osler joked that Canada would profit from an export tax on all the "Canadian girls" becoming Hopkins nurses. ${ }^{7}$ In 1893, an American student nurse complained that "the Canadians will overpower us." Archival data confirm Osler was troubled by criticisms that he had overpopulated Hopkins with Canadians. ${ }^{1}$

The selection of residents and interns was at the discretion of each chief. The advancement of nurses was decided by the nursing superintendent, often in consultation with chiefs. Personality mattered, Osler explained, because they "come in contact with us at all hours" and must be "persons with whom we can work pleasantly and congenially." ${ }^{1}$ Some of those were inspired to train at the elite Johns Hopkins by their fellow Canadians in leadership positions there. Adelaide Nutting chose Hopkins for its "unusual opportunities for training in nursing" under the reassuring tutelage of Canadians Isabelle Hampton, William Osler and Henri Lafleur. ${ }^{8}$ Nutting succeeded her teacher as nursing superintendent in 1895. Lewellys Barker, who succeeded Osler in 1905, was a young Toronto physician motivated to do postgraduate work after reading the first issue of The Johns Hopkins Hospital Bulletin (Figure 1). Barker recalled how Osler's success in Baltimore had spurred his own desire for a position at Hopkins. ${ }^{9}$ Osler had worked with Henri Lafleur at McGill and recruited him to be first chief resident, in charge of the medical wards, clinical laboratories and postgraduate interns at Hopkins.

There are indications that members of this leadership group self-identified as "Canadian" in ways that were distinct from both British and American identities. When Osler welcomed the British Medical Association meeting to Montréal in 1897, he noted the centuries of bloodshed caused by the English, French and Americans who had fought for control of Canada. He assured his fellow physicians from those countries that, nevertheless, "we Canadians" could forget past enmities "to welcome you to our country" (he had been living in the US for 13 years). ${ }^{10}$

Archival sources contain a subtext that living in America threatened inherently Canadian traits or values. Nutting's approach to nursing education was famously militaristic. "I shall be very severe and rigid," she told her family when she was promoted to superintendent, adding the reassurance: "If I lived here 50 years, I should still be the warmest kind of Canadian." Osler revealed similar concerns when he confessed to a colleague that he did not want his son "brought up an American."

The Johns Hopkins ethos permeated the evolution of nursing and medical education in 20th-century North America. Osler imported clinical teaching and bed- side instruction to American medical education, pedagogical approaches introduced much earlier in Canadian medical schools because of undisturbed ties to British and French traditions. The Hopkins model was also shaped, however, by the individual choices and sensibilities of Osler and other key teachers and administrators. Almost $40 \%$ of these early leaders were Canadian, and I have highlighted how historical analyses of the perception, selection and self-identification of this group could clarify whether an identifiable "Canadian personality" or influence shaped the new medical mecca.

\section{Susan Lamb PhD}

Jason A. Hannah Chair in History of Medicine, Department of Innovation and Medical Education, Faculty of Medicine, University of Ottawa, Ottawa, Ont.

\section{References}

1. Unpublished archival source (i.e., private correspondence or meeting minutes). For complete citations, please contact the author.

2. Harvey AM, Brieger GH, Abrams SL, et al. A model of its kind. JAMA 1989;261:3136-42.

3. Billings JS. Johns Hopkins Hospital, Baltimore: Reports and papers relating to construction and organization, no. 1 [letter]. Baltimore; 1876.

4. Bernheim B. The story of Johns Hopkins. New York: Whittlesey House; 1948.

5. Bliss M. William Osler: a life in medicine. Toronto: University of Toronto Press; 1999.

6. Jarrett WH. Yale, Skull and Bones, and the beginnings of Johns Hopkins. Proc Bayl Univ Med Cent 2011; 24:27-34.

7. Osler W. Baltimore American, 1905 Apr 1: 2

8. Johns E, Pfefferkorn B, editors. The Johns Hopkins School of Nursing, 1889-1949. Baltimore: Johns Hopkins University Press; 1954.

9. Barker LF. Dr. Osler as the young physician's friend and exemplar, Bulletin no. IX, Sir William Osler memorial number. Montréal: International Association of Medical Museums; J Technical Methods 1926:251-8.

10. Osler W. British medicine in Greater Britain. In: Aequanimitas, with other addresses to medical students, nurses and practitioners of medicine. Philadelphia: P. Blakiston's Son; 1928.

Susan Lamb received grants from Associated Medical Services during the conduct of the study.

This article was solicited and has been peer reviewed.

The author wishes to dedicate this work to Professor Michael Bliss (1941-2017), in honour of his outstanding commitment to scholarship and mentorship in history of medicine. 